\title{
Integrating Waste Management and Pollution Control in Tertiary Vocational Education Programmes: Case Studies
}

\author{
Mary Panko and Rashika Sharma
}

\begin{abstract}
Strategies to minimise pollution and environmental damage must start with the training of students ready to take their places in industry. These case studies show that by immersing students in the practicalities of waste management, they acquire a deeper understanding of the wider principles of pollution control. Degree students had to climb into waste bins, analyse the contents and research recycling opportunities. To investigate the extent to which this process had made an impact on them, they completed a questionnaire which explored their attitudes in relation to waste management and to the way in which they had been introduced to the topic. A second case study examined the views of International students about sustainability. Both studies showed that they considered the subject valuable and would apply wider principles of sustainability once they were employed in their chosen profession and in their own countries.
\end{abstract}

Index Terms-Waste management, pollution control, product life-cycles, quadruple bottom line, vocational education.

\section{INTRODUCTION}

If tertiary graduates do not have a core understanding of sustainability, then the pathway to a sustainable future will remain a side road for longer than necessary [1].

Strategies to minimize pollution and damage to the environment do not have a single starting or finishing point. By the nature of our changing world, allied to the continual revolution of technologies, these are issues that have to be continually re-examined. However, one starting point has to be with the students who are currently being educated to take their places in industries across the globe. Given the importance of this principle, this paper unequivocally makes a case for the integration of sustainability concepts, such as waste management and pollution control, into the Tertiary Education curriculum of all vocational students, in a manner that will allow undergraduates to see its relevance within their own lives and then be able to apply aspects of it in meaningful ways once they join the workforce. In addition, this argument calls on the reader to recognize ways in which this integration directly affects all professions and peoples, regardless of political persuasion.

Sustainability is frequently synonymous with the Quadruple Bottom Line, where studies focus on four basic and interlocking premises: Environmental effects, Governance, Societal Impact and Economic principles of processes or products. For a systematic appreciation of these threads, sustainable curricula normally link these four

Manuscript received July 21, 2014; revised October 21, 2014.

The authors are with Unitec Institute of Technology, Auckland, New Zealand (e-mail: mpanko@unitec.ac.nz,rsharma@unitec.ac.n). concepts to the Life-cycle of particular products or processes and distinguish which stage of the life cycle has the greatest impact, for benefit or for harm [2].

\section{LITERATURE}

United Nations Decade for Education for Sustainable Development (2005-2015) provided guideline for all educational levels to embed education for sustainability. As this decade draws to a close, it is an appropriate time to reflect on the environmental perspectives of students and consider whether these have changed as a result of their learning experiences. Literature has highlighted that environmental perspectives are directly influenced by students' involvement with sustainability issues. A research conducted on Australian apprentices' and trainees' confirms that environmental perspectives of participants' improve significantly after engaging with sustainability skills [3].

Evidence of a growing commitment to sustainable higher education can be found across the globe, from North America, Europe to Australasia. For example, while trans-disciplinary sustainability education is being promoted in Canada at the University of British Columbia [4], in the United States, some smaller universities are not only grappling with curriculum implementation but also examining ways through which they can practically apply sustainable practices within their own campuses [5].

In Europe, similar transnational developments are progressing. Almost two decades ago representatives of all European nations agreed to the COPERNICUS Charter for Sustainable Development in the European Higher Education Area [6] which focussed on the following:

- supporting existing innovative approaches to elaborate modules on sustainable development for modularized study courses;

- improving the contribution of higher education institutions to sustainable development, in particular to creating equal standards of living;

- strengthening the role of higher education institutions in society based upon the principles of sustainable development and solidarity;

- improving the future compatibility and innovation potential of higher education institutions and,

- making a long-term contribution to the UN Decade on Education for Sustainable Development.

One of the most significant aspects of our own research in this area has been the realization that students need to be able to see that their actions can make an impact in the world [2] comparable investigation conducted in the UK [7] provided similar positive results but additionally indicated a sense of 
futility amongst the students regarding the future of society in the face of broad-based environmental challenges. Although many of the students surveyed in the UK thought that environmental sustainability was a 'good thing', few were aware of the wider social, political and economic dimensions of sustainable development. Furthermore they considered that the problem was too overwhelming for them to consider, let alone attempt to improve.

Methods to encourage a student to understand rather than simply 'know' have been explored in the literature of teaching and learning through many different aspects. One of oldest has been through aspects of 'active learning' where the student engages directly with the material in a practical manner, also known as 'learning by doing,' [8]. This parallels the concepts of experiential learning theory [9] in that it is not only the 'experience' itself that may be transformative, it is that deeper layer of learning where the student is required to reflect on their experience where understanding becomes significant. It is hoped that at this point students contribute critical judgements on what has been discovered.

Fien and Maclean [10] have expressed this as follows:

All cultures, communities, individuals and workplaces have their own views on what such values and principles should be. Given the need for sustainable development to be locally relevant and culturally appropriate, it is not possible to outline specific values to be encouraged by TVET. However, programmes should encourage students to reflect upon their own values, how they affect lifestyle choices and the social, economic and environmental impacts that would result if everyone in the world believed and acted as they did.

This philosophy requires the development of both critical thinking and practical skills which in turn has led us to encourage the integration of practical sustainability and waste management into the teaching sessions.

\section{BACKGROUND}

The students who participated in this case study were enrolled in The Bachelor of Applied Technology and were likely to move into practical careers once qualified. A large proportion of these students were international, coming from countries such as Saudi Arabia, Malaysia and China (Fig. 1), and the majority expected to return to their home countries to practice in their professions after graduation.

For part of their assessment in Semester 1, 2014, students were required to participate in a construction waste management project on the Unitec campus. Jaques' guidelines [11] were used to target the five stages of waste and pollution reduction by focusing on: Reduction; Reuse; Recycling; Recovery and Residual disposal.

As our students were from four main discipline areas: Boat building, Automotive, Electrotechnology and Building Technology, they were additionally required to report on pollution and waste management issues from their own specialisation's perspective, which may have had different points of impact, depending on the quadruple bottom line and relevant life cycle.

The four aspects of the Quadruple bottom line must be examined through the impact they make on each life-cycle stage, from manufacture, use and finally decommissioning.
These stages are tightly interrelated with one another and, depending on the nature of the product or process, tend to exert major negative effects at different parts of their life cycle.

\section{A. The Quadruple Bottom Line and Product Life-Cycles}

The four aspects of the Quadruple Bottom Line examined by the students were: The Environment, Society, Economics and Governance. In turn each of these were studied in terms of potential pollution and waste management problems during manufacture, while in use and finally, during decommissioning. In addition, embedded energy consumption was also considered, along with the necessity for health and safety and environmental audits.

When considering the automotive industry, it is well known that substantial pollution hazards exist at every stage of the life cycle and in every aspect of the industry, from ore and oil extraction and manufacturing, through pollution during use, to decommissioning of tyres, batteries and whole vehicles in the final stages. Students however, also needed to be aware that changes in technology, such as the adoption of battery driven cars could minimise one form of pollution (that from petrol) only to increase another (rare earths used in battery manufacture).

With some other industries, the negative impacts can still be identified but these may occur at fewer stages in the life cycle. For example, when examining yacht building and design, while there is may be low impact at the manufacturing stage, during the functioning life of a wind propelled boat the major issue is likely to be aquatic pollution resulting from painting and anti-fouling treatments. However, if the boat has been built using modern carbon fibre technologies, there is also a significant problem when the boat needs to be decommissioned as carbon fibre is currently not easily recycled.

\section{RESEARCH METHOD}

Sixty second year students participated in the project. They were required to apply the guidelines provided by Jaques [11] which emphasise the $5 \mathrm{Rs}$ and also provide examples of the way in which these can be achieved:

- Reduce

- Reuse

- Recycle

- Recover and

- Residual disposal

Teams of five or six students examined the construction waste bins around the Unitec campus and created an inventory of all the waste they identified. Then each team had to collaboratively debate online examples of the $5 \mathrm{Rs}$ for all the material they had found. This included the various categories of waste identified and research options available to re-cycle or up-cycle all of this material, at each stage of a product's life cycle, from sensitive design to careful deconstruction. The students were then required to reflect on ways through which waste and pollution could be minimised, particularly within their own industries.

However, in addition to exploring students' awareness of waste management concepts we also hoped to explore their 
attitudes and values as well as their knowledge of required skills both across the general TVET community and within international students in particular.

For the International study 22 students participated in an Online questionnaire. Their ethnicities were diverse (Fig. 1).

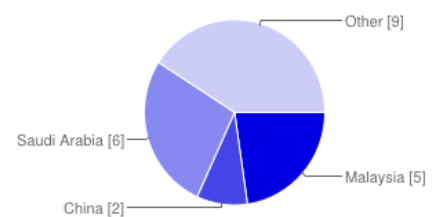

Fig. 1. State of origin for the international students.

At the conclusion of the waste management project students were asked to complete a questionnaire that was designed to discover to what extent, if any, their understanding of waste management had been transformed by this process.

\section{FINDINGS}

When the students' online records were examined, the depth of reflection and critique varied amongst the different groups, and this seemed to depend on the lead set by the early contributors. This meant that while some groups considered a combination of factors including ways to limit the waste being produced initially, as well as researching recycling options for the different materials, other groups took a more superficial approach. Unfortunately, this is one of the disadvantages that working in small online groups is known to create [12]. In addition, fewer students than we had hoped took the additional step of relating what they had seen in the building industry to their own disciplines in any detail.

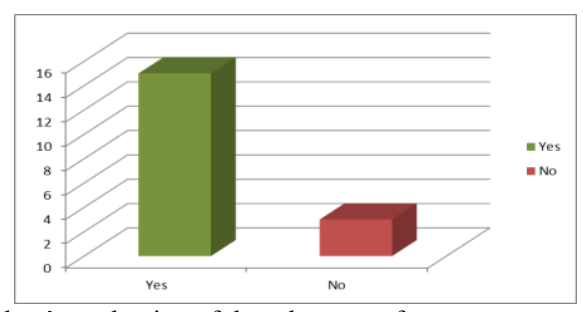

Fig. 2. Student's evaluation of the relevance of waste management in their industry.

Nevertheless, their responses to the questionnaire revealed that all the participants considered waste to be an extremely important issue for their respective industries and felt that they were now able to relate waste with their own specializations. Students showed greater awareness of waste and we able to relate its significance and relevance to their particular industries as indicated in Fig. 2. Out of the 60 students who participated in the exercise 16 responded to the questionnaire. Out of these, 14 students found the exercise beneficial and they agreed that reduction of pollution and waste management control were elements of their learning that they would attempt to instill into their practice after qualifying.

Students were beginning to identify how their various industries were playing a critical role in waste generation and their ability to reflect on the current practices showcased their increase in environmental awareness. Table I presents the key statements applicable to each discipline.

One student noted that:

"We came across a large amount of metal 'off cuts' which seems to have come from pipe welding ... the reduction of this metal waste could have easily been overcome by simply measuring the exact material that is needed and make use of the entire pipe opposed to cutting at random lengths which left us with the "off cuts'."

This seemingly simple observation indicates that students were now thinking about the full life-cycle picture of sustainability and not solely focusing on waste recycling.

Students also expressed their surprise during the teaching sessions that alterations in initial design could make a major difference when it came to recycling end-of-use materials, such as electronic waste. The students came to realise that lack of good design considerations frequently meant that metals could not be separated from the other components and again this was emphasized in a practical way by handing them quantities of electronic waste during class as a topic for discussion.

TABLE I: KEY STATEMENTS - DISCIPLINE RELATED

\begin{tabular}{|l|l|}
\hline Automotive & $\begin{array}{l}\text { - there are many factors that the automotive industry } \\
\text { are addressing. e.g. emissions and have control } \\
\text { strategies in place } \\
\text { - oil can't be recycled and can't throw away in public } \\
\text { places } \\
\text { - in auto industry lot of metal, plastic, rubber etc. } \\
\text { involve during manufacturing new vehicles \& they } \\
\text { most are recyclable for further use } \\
\text { - the unwanted tires from customer }\end{array}$ \\
\hline Electrical & $\begin{array}{l}\text { - technology is changing everyday and a lot of old } \\
\text { tech is obsolete and need to be recycling properly } \\
\text { environment everyday are many electrical waste getting into our } \\
\text { - the electrical industry deal with a lot of wires and } \\
\text { cable which produce plastic cable waste and metal } \\
\text { waste }\end{array}$ \\
\hline
\end{tabular}

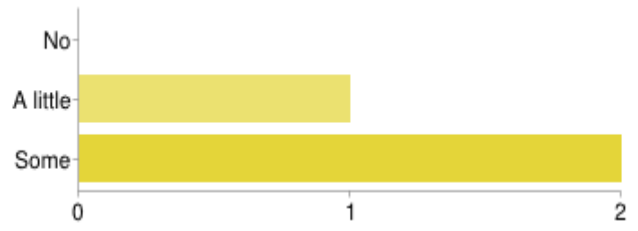

Fig. 3. Potential application of sustainable practices.

When the perceptions of international students were examined it showed that while all thought that little notice was currently being taken of waste management at the present time the majority believed that there was a great potential for sustainability in their own countries (Fig. 3).

In yet another on-going study a student in the final year of his Bachelor of Applied Technology degree is currently analyzing volumes of construction waste production in relation to two features: the practical experience of the selected target groups and the numbers of students involved in the completion of different houses. This research, which will be discussed further once the work is completed, indicated that waste management studies are being increasing regarded as a fundamental topic in the education of vocational students.

\section{DISCUSSION AND CONCLUSION}

This study and others [13], [14] convinced us of the prime 
importance of integrating sustainability, including waste management and pollution control, into our degree courses. They have also demonstrated that the greater the 'hands-on' nature of the students' experiences, the greater they see the relevance of their learning. The notion that environmental education in any form (waste management) when embedded into education creates consciousness to act responsibly towards the environment is clearly supported by this research.

Nevertheless, several barriers still exist to restrict the incorporation of sustainability into practical education programs. Research undertaken in New Zealand [15] indicated that there were fundamental differences in opinion about the role of education for sustainability between students on one hand and their lecturers and industry personnel on the other. Students felt optimistic about the opportunities offered by sustainability whereas the latter saw little relevance for it. The academics main arguments were that:

- Time spent on 'soft-issues' like sustainability was time lost on what they saw as the rightful core of their discipline topics;

- They did not have sufficient knowledge to develop this aspect for students;

- Additional topics would adversely contribute to workload problems;

- Finally, both academics and industry representatives saw sustainability as contributing additional expense and could only see its worth in terms of immediate economic viability.

Recent informal research has shown there may be another unexpected barrier which is the belief held by some tertiary lecturers that they do currently teach sustainability issues within their own disciplines and therefore, nothing further needs to be considered. They point to one part of a product or process life cycle, frequently selecting the stage of 'recycling', and explain that therefore the topic is covered - in full. However, while addressing the issue of sustainability to any extent can be seen as an educational gain, it is important that a wider challenge is offered to tertiary students.

However, the greatest value of their education appears to be in the hope it provides for the dissemination of this awareness into the work environment once they have graduated. In order to highlight the relevance of these issues students must be encouraged to audit their industries for the environmental strengths of the work environment and be able to identify improvements in procedures which would lead to alternative possibilities for action in regard to waste management reduction.

Drawing these strands together, these results indicate that providing both local and international vocational students with increased awareness of 'green' issues relevant to their industry will be of significant importance in the coming decades. Our studies show that practical high lightening of waste and pollution management is an essential first step in educating the workforce of tomorrow.

\section{REFERENCES}

[1] Parliamentary Commissioner for the Environment, See Change: Learning and Education for Sustainability, Wellington, P.E.C., 2004

[2] M. Panko, "A curriculum for sustainability throughout tertiary education," The International Higher Education Curriculum Design Review, vol. 1, pp. 71-80, 2012.
[3] M. Brown and F. Sack. "What do VET students and graduates think about 'skills for sustainability'?" in Proc. in Ted Griffin, NCVER, Adelaide, 2012

[4] Y. Sipos, B. Battisti, and K. Grimm, "Achieving transformative sustainability learning: Engaging head, hands and heart," International Journal of Sustainability in Higher Education, vol. 9, no. 1, pp. 68-86, 2008.

[5] K. J. Krizek, D. Newport, J. White, and A. R. Townsend, "Higher education's sustainability imperative: how to practically respond?" International Journal of Sustainability in Higher Education, vol. 13, no. 1, pp. 19-33, 2012

[6] Copernicus Charter for Sustainable Development in the European Higher Education Area. (1994). [Online]. Available: http://www.unece.org/fileadmin/DAM/env/esd/information/COPERN ICUS\%20Guidelines.pdf

[7] F. Kagawa, "Dissonance in students' perceptions of sustainable development and sustainability: Implications for curriculum change," International Journal of Sustainability in Higher Education, vol. 8, no. 3, pp. 317-338, 2007.

[8] C. Meyers and T. B. Jones, Promoting Active Learning, Strategies for the College Classroom, San Francisco, CA: Jossey-Bass, 1993.

[9] D. A. Kolb, R. E. Boyatzis, and C. Mainemelis, "Experiential learning theory: Previous research and new directions," in Perspectives on Thinking, Learning, and Cognitive Styles, R. J. Sternberg and L.-F. Zhang, Ed., Mahwah: NJ Lawrence Erlbaum, Inc., ch. 9, pp. 227-246, 2001.

[10] J. Fien and R. Maclean, "Introduction: The legacy of the bonn declaration," Work, Learning and Sustainable Development: Opportunities and Challenges, vol. 8, 2009.

[11] R. Jaques, Building Basics: Minimising Waste, Porirua, New Zealand: Branz, 2013

[12] M. Panko, "Small group learning in online discussions: staying in your own backyard or peering over the garden fence?" in Proc. ASCILITE 19th Annual Conference, Unitec, Auckland, December 9-11, 2002.

[13] M. Panko, R. Sharma, and D. Fuemana, "Waste not, want not: Education for sustainability in the construction industry," presented at Building a Better New Zealand Conference, Auckland, September, 2014.

[14] E. Redmen, "Advancing educational pedagogy for sustainability: developing and implementing programs to transform behaviours," International Journal of Environmental Science Education, vol. 4, no. 1, pp. 1-34, 2013.

[15] R. Sharma, "Collaborative partnership for education for sustainability: New Zealand vocational education," The International Journal of Sustainability in Higher Education, vol. 9, no. 1, pp. 68-86, 2011.

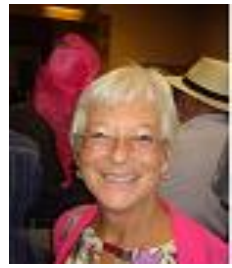

M. Panko was born and educated in the United Kingdom where she graduated from Aberdeen University with an honours degree in zoology. After moving to New Zealand in 1994 she gained a graduate diploma in higher education, followed by the award of a PhD in education in 2004 from The University of New England at Armidale, New South Wales, Australia.

Mary became a programme director for the graduate diploma of education at Unitec Institute of Technology in 1995 and then, after becoming a senior lecturer in the same institution, became a programme director for the master of education.

In 2011 she transferred to the Department of Building Technology at Unitec where she is currently employed part-time, lecturing in sustainability and mentoring the research of her colleagues. In addition, in 2012 she was appointed as the research development director for the New Zealand Curriculum Development Institute. In February 2014 she published an edited text: "Developing a research culture: A guidebook for everyone".

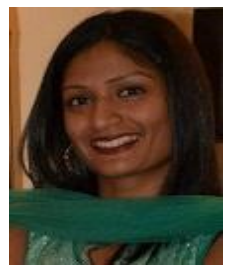

R. Sharma is a lecturer in integrated practice at Unitec Institute of Technology in New Zealand specialising in sustainable practice, societal context and generic skills on the bachelor of applied technology degree.

Rashika is currently pursuing a doctoral degree in education from Deakin University in Australia and holds a master's degree in education from Unitec Institute of Technology. Prior to this Rashika was awarded with the graduate diploma in higher education from Unitec.

Rashika's research focus is on education for sustainability and she has written widely in this area. She also takes keen interest in student centred teaching and learning strategies. Previously Rashika taught at the Fiji Institute of Technology in Suva, Fiji. 